\title{
OS GRUPOS DE PESQUISA EM POLÍTICA EDUCACIONAL DA REGIÃO NORTE: mapeamento e breves reflexões
}

\author{
Mark Clark Assen de Carvalho' \\ Adão Rogério Xavier Silva² \\ Dinair Leal da Hora
}

\section{RESUMO}

O estudo tem como objetivo mapear os Grupos de Pesquisa em Políticas Públicas Educacionais existentes e em atividade nas Instituições de Ensino Superior (IES) públicas da região Norte do Brasil e devidamente registrados no Diretório dos Grupos de Pesquisa (DGP) do Conselho Nacional de Desenvolvimento Científico e Tecnológico (CNPq). Trata-se, portanto, de uma pesquisa descritiva de abordagem quali-quantitativa, cuja coleta de dados se deu a partir de consultas parametrizadas em website do DGP do CNPq. A partir dos dados gerais, busca-se traçar o perfil dos Grupos de Pesquisa, seus/suas respectivos(as) pesquisadores(as) e linhas de pesquisa. Como resultado, estratificou-se a existência de 95 Grupos de Pesquisa, sendo que 78 destes estão vinculados às universidades públicas federais, 07 a Institutos Federais de Educação, Ciência e Tecnologia do Amazonas e outros 10 a universidades públicas estatuais amazônicas. Do quantitativo geral dos grupos, identificou-se que $69 \%$ dos(as) líderes dos grupos é pertencente ao sexo feminino, ou seja, são mulheres, professoras/pesquisadoras. Além da incidência da temática, identificou-se, também, que 91,6\% dos(as) líderes possuem titulação de doutorado e pós-doutorado e estão majoritariamente vinculados a linhas de pesquisa segmentadas no campo da política educacional.

Palavras-chave: Política pública educacional. Grupos de pesquisa. Região Norte. Diretório dos Grupos de Pesquisa.

\footnotetext{
${ }^{1}$ Doutor em Educação (PUC-SP). Professor Titular da Universidade Federal do Acre (UFAC) e Professor Permanente do Programa de Pós-Graduação em Educação da UFAC e do e do Programa de Pós-Graduação em Educação na Amazônia (PGEDA) Rede/EDUCANORTE. ORCID iD: https://orcid.org/0000-0003-3638-9719. E-mail: markassen@yahoo.com.br

${ }^{2}$ Doutorando em Educação pelo Programa de Pós-Graduação em Educação na Amazônia (PGEDA) Rede/EDUCANORTE, pela Universidade Federal do Pará (UFPA). Membro do Núcleo de Estudos e Pesquisas em Política Educacional, Gestão e Financiamento da Educação da Universidade Federal do Acre (UFAC). ORCID iD: https://orcid.org/0000-0003-0277-3392. Email: adaorxs@gmail.com

${ }^{3}$ Doutora em Educação (Unicamp). Professora Adjunta da Universidade Federal do Pará (UFPA), lotada no Campus Universitário de Abaetetuba e professora permanente do Programa de Pós-Graduação em Currículo e Gestão da Escola Básica da UPFA e do Programa de Pós-Graduação em Educação na Amazônia (PGEDA) Rede/EDUCANORTE. ORCID iD: https://orcid.org/0000-0002-3278-3914. E-mail: tucupi@uol.com.br
} 


\title{
THE RESEARCH GROUPS IN EDUCATIONAL POLICY IN THE NORTHERN REGION:
}

\author{
mapping and brief reflections
}

\begin{abstract}
The study aims to map the existing and active Research Groups in Public Educational Policies in public Higher Education Institutions (HEls) in the North of Brazil and duly registered in the Directory of Research Groups (DGP) of the National Council for Scientific Development and Technological (CNPq). It is, therefore, a descriptive research with a quali-quantitative approach, whose data collection took place from parameterized queries on the CNPq DGP website. From the general data, we seek to draw the profile of the Research Groups, their respective researchers and lines of research. As a result, the existence of 95 Research Groups was stratified, 78 of which are linked to federal public universities, 07 to Federal Institutes of Education, Science and Technology of Amazonas and another 10 to state Amazonian public universities. From the general quantitative of the groups, it was identified that $69 \%$ of the group leaders belong to the female sex, that is, they are women, teachers/researchers. In addition to the incidence of the theme, it was also identified that $91.6 \%$ of the leaders have a doctorate and postdoctoral degree and are mostly linked to segmented lines of research in the field of educational policy.
\end{abstract}

Keywords: Educational public policy. Research groups. North region. Directory of Research Groups.

\section{LOS GRUPOS DE INVESTIGACIÓN DE POLÍTICAS EDUCATIVAS EN LA REGIÓN}

\section{NORTE: mapeo y breves reflexiones}

\section{RESUMEN}

El estudio tiene como objetivo mapear los Grupos de Investigación existentes y activos en Políticas Públicas Educativas en Instituciones Públicas de Educación Superior (IES) del Norte de Brasil y debidamente registrados en el Directorio de Grupos de Investigación (DGP) del Consejo Nacional de Desarrollo Científico y Tecnológico ( $\mathrm{CNPq}$ ). Se trata, por tanto, de una investigación descriptiva con enfoque cuali-cuantitativo, cuya recogida de datos se realizó a partir de consultas parametrizadas en el sitio web CNPq DGP. A partir de los datos generales, buscamos trazar el perfil de los Grupos de Investigación, sus respectivos investigadores y líneas de investigación. Como resultado, se estratificó la existencia de 95 Grupos de Investigación, 78 de los cuales están vinculados a universidades públicas federales, 07 a Institutos Federales de Educación, Ciencia y Tecnología de Amazonas y otros 10 a universidades públicas amazónicas estatales. A partir de la cuantitativa general de los grupos, se identificó que el $69 \%$ de los líderes de grupo pertenecen al sexo femenino, es decir, son mujeres, docentes / investigadoras. Además de la incidencia de la temática, también se identificó que el 91,6\% de los líderes tienen un doctorado y posdoctorado y en su mayoría están vinculados a líneas de investigación segmentadas en el campo de la política educativa.

Palabras clave: Política pública educativa. Grupos de investigación. Región del norte. Directorio de Grupos de Investigación. 


\section{INTRODUÇÃO}

Da curiosidade ingênua que caracterizava a leitura pouco rigorosa do mundo à curiosidade exigente, metodizada com rigor, que procura achados com maior exatidão. O que significou mudar também a possibilidade de conhecer, de ir mais além de um conhecimento opinativo pela capacidade de apreender com rigor crescente a razão de ser do objeto da curiosidade (FREIRE, 1993, p. 09).

A epígrafe acima, extraída da seção intitulada Primeiras Palavras, da obra Política e Educação (1993), escrita por Paulo Freire, Patrono da Educação Brasileira ${ }^{4}$, faz-nos lembrar algo que é constitutivo do ser humano, oriundo do processo de interações e das práticas sociais e culturais de produzir-se socialmente, mudando, em uma perspectiva constante, as leituras e suas interações com o mundo.

Desse modo, havendo vida e/em interação social, o conhecimento, como produção eminentemente social, resulta da ação e reflexão teleológica ocasionada pela "curiosidade em constante movimento de procura", que "se aprimora e se aprofunda com a existência humana" (FREIRE, 1993, p. 08).

Valendo-se de Freire (1993), o estudo que aqui apresentamos sustenta a ideia de que a "curiosidade exigente", em seu constante movimento permeado nas relações sócio humanas no espaço e no tempo, se aprimora e se aprofunda, autenticando e ressignificando constantemente as abordagens, técnicas, métodos e teorias de análise dos objetos de pesquisa.

Envoltos nessa reflexão, é que surge a questão deste estudo: como estão sendo conduzidas as "curiosidades exigentes" - em outras palavras: as pesquisas - em Políticas Públicas Educacionais dos Grupos de Pesquisas das universidades públicas da região Norte do Brasil?

Nessa direção, a busca por possíveis respostas, organizamos a partir da formulação do seguinte objetivo: tracejar, caracterizar e quantificar os Grupos de Pesquisa em Políticas Públicas Educacionais, devidamente certificados no Diretório dos Grupos de Pesquisa (DGP) do Conselho

\footnotetext{
${ }^{4}$ Conforme Lei $n^{\circ} 12.612$, de 13 de abril de 2012.
} 
Nacional de Desenvolvimento Científico e Tecnológico (CNPq) e em atividade nas instituições públicas de ensino superior da região Norte do Brasil.

Trata-se de estudo de natureza descritiva e analítica, que se organiza a partir de uma abordagem quali-quantitativa, cuja coleta de coleta de dados se deu a partir de consultas parametrizadas em website do DGP do CNPq, em intersecção com os sites de alguns dos Programas de Pósgraduação em Educação.

Nesse sentido, o texto está organizado em três partes, além desta breve introdução e das considerações finais. Na primeira parte, tecemos algumas demarcações históricas da constituição do campo de pesquisa em Políticas Públicas Educacionais no Brasil para, na sequência, fazermos a exposição dos procedimentos metodológicos utilizados para realizar o levantamento dos dados, os quais servirão para que, na terceira parte, sejam apresentados e analisados os dados que servem para delinear o perfil dos grupos de pesquisa identificados e analisados.

\section{DEMARCAÇÕES HISTÓRICAS DA PESQUISA EM POLÍTICAS PÚBLICAS EDUCACIONAIS NO BRASIL}

Referirmo-nos à história constitutiva do campo de pesquisa em políticas públicas educacionais no Brasil, ainda que brevemente, é fundamental para melhor compreendermos sua trajetória, desdobramentos, perspectivas e sua inserção na pesquisa educacional. Nesse sentido, optamos por pautar uma breve revisão de literatura a partir do estudo realizado por Stremel (2016), que, em sua tese de doutoramento, analisou a constituição do campo acadêmico da política educacional no Brasil.

$\mathrm{Na}$ pesquisa, a referida autora utiliza do arcabouço teórico e metodológico do sociólogo francês Pierre Felix Bourdieu, dos conceitos de campos, habitus e capital. E, também, de autores que tratam da institucionalização de um determinado campo, como: Gómes Campo e Tenti Fanfani (1989), Suasnábar e Palamidessi (2007). Apoiou-se, ainda, na fundamentação do conceito de política educacional e seus objetivos, 
propostos nos estudos de Ball (1994), Rizvi e Linguard (2010), dentre outros. Além disso, buscou âncoras nas pesquisas sobre a história e a produção do conhecimento no campo da política educacional, a partir dos estudos de Azevedo e Aguiar (2001), Santos (2009) e outros.

Preliminarmente, o que depreendemos do seu constructo teórico é o cuidado no trato em enveredar-se por um caminho que perpassa distintos campos do conhecimento, construídos por diversas variáveis, aos quais diferentes agentes e instituições se agremiaram - e se agremiam - em contextos de dissensos e consensos internos e externos. Assim, é dessa forma que Stremel (2016) conduz sua investigação, buscando compreender o seu objeto no interior do contexto histórico, político e educacional brasileiro.

No que tange aos aspectos da natureza da referida pesquisa, apresenta uma abordagem qualitativa, centrada na análise documental e bibliográfica, a partir de boletins e anais da ANPEd e Anpae, documentos da Capes e CNPq, periódicos e outras produções científicas vinculadas ao campo da política educacional no Brasil. A autora também utilizou, como coleta de dados, entrevista com duas pesquisadoras do campo acadêmico da política educacional, sem perder de vista, a consideração dos processos que permearam (e permeiam) a institucionalização e expansão da política educacional no Brasil como um campo específico.

Stremel (2016) aponta que a constituição do campo se situa a partir da criação das associações científicas e grupos de trabalhos, de disciplinas, de linhas e grupos de pesquisas vinculados às universidades. São, portanto, esses elementos que influíram e influem diretamente nas publicações especializadas, nas organizações dos eventos científicos da área e nas consolidações das redes de pesquisas, pilares constitutivos do campo acadêmico da política educacional no Brasil (STREMEL, 2016).

É importante, aqui, balizar, conforme observa Stremel (2016), a complexidade em definir um ponto de partida, dado aos imbricamentos do processo de constituição a outros campos de conhecimento, visto que, no caso do campo da política educacional, "seus antecedentes estão ligados ao campo da administração da educação, administração educacional e 
educação comparada" (STREMEL, 2016, p. 112). Assim, em conformidade com a autora, optamos, neste estudo, por fixar, como primeiro marco do processo de institucionalização do campo5, a criação da Anpae, em 1961.

Nessa direção, verificamos que, no Brasil, a Política Educacional vem se configurando como um campo acadêmico específico a partir da década de 1960, totalmente incentivado e demarcado pelos seguintes aspectos:

1) a criação da ANPAE em 1961;

2) o uso mais frequente do termo política(s) educacional(is) nos títulos de teses, dissertações, artigos e livros;

3) a implantação da Pós-Graduação (1965) e do primeiro Mestrado em Educação (PUC-Rio, 1966), momento em que a pesquisa em educação no Brasil é incorporada pelo campo acadêmico (STREMEL, 2016, p. 79).

Entretanto, ainda que transcorridas seis décadas desde a materialização de tais aspectos, a autora adverte que, de maneira geral, trata-se de um campo em construção, posto que "ainda faz-se necessário ampliar as formulações e teorizações próprias do campo" (STREMEL, 1960, p. 80). Considerando a riqueza e densidade das informações levantadas pela autora, bem como as limitações deste estudo, optamos por tecer, aqui, algumas considerações somente do primeiro aspecto, dada a sua relevância propulsora na sequencialidade dos aspectos subsequentes.

Em atenção ao primeiro aspecto, a criação da Associação Nacional de Professores de Administração Escolar (Anpae) no ano de 1961 - hoje Associação Nacional de Política e Administração da Educação, sabemos que a entidade foi instituída por um grupo de pesquisadores(as) e professores(as) reunidos na antiga faculdade de Filosofia, Ciência e Letras da Universidade de São Paulo (USP), em função da participação no I Simpósio Brasileiro de Administração Escolar. Conforme Sander (2007),

A ANPAE foi concebida com a missão de lutar pelo exercício do direito à educação de qualidade para todos, através de sua participação na formulação de políticas públicas de educação e na

5 Para se ter uma vista mais ampla dos antecedentes, ver Stremel (2016) Capítulo 2. 
concepção e adoção de práticas de gestão democrática, alicerçadas nos princípios e valores da solidariedade e justiça social e da liberdade e igualdade de direitos e deveres na educação e na sociedade (SANDER, 2007, n/p).

Ainda conforme Sander (2007), lê-se que a trajetória da Anpae se reflete na própria trajetória da gestão da educação exercida como campo de pesquisa e nas instituições de ensino, isto é, nos constitutivos presentes no pensamento pedagógico e administrativos da educação brasileira nos últimos 50 anos. Tal fato possibilita compreender os cinco processos de rebatizamento pelos quais a entidade passou ao longo desse período: 1961 Associação Nacional de Professores de Administração Escolar; 1971 Associação Nacional de Profissionais de Administração Escolar; 1976 Associação Nacional de Profissionais de Administração Educacional; 1980 Associação Nacional de Profissionais de Administração da Educação; 1996 Associação Nacional de Política e Administração da Educaçãob, vigente até os dias atuais.

Nessa ambiência é que constatamos a sua ativa atuação no que se refere à promoção e socialização do conhecimento sistematizado, a considerar que a Anpae é uma das principais entidades brasileiras que comportou e comporta um espaço privilegiado para o encontro de pesquisadoras e pesquisadores do campo educacional em suas mais variadas instâncias. Cabe sinalizar, ainda, sua contribuição na manutenção da periodicidade da Revista Brasileira de Política e Administração da Educação (RBPAE)7, cujo objetivo filia-se a difundir os estudos e experiências educacionais, promovendo o debate e a reflexão do campo teórico e prático da gestão da educação, processos de planejamento, formulações, avaliações de políticas educacionais no âmbito do ensino, escolas, universidades e outros espaços públicos de educação.

Nessa direção,

\footnotetext{
6 Para se ter uma vista mais ampla dessa discussão, ver Sander (2007), disponível em: https://www.anpae.org.br/website/documentos/estudos/estudos_01.pdf Acesso em 23 de outubro de 2021.

7 Ver https://seer.ufrgs.br/rbpae.
} 
ANPAE marcou presença na genealogia do conhecimento no campo da gestão da educação brasileira e participou de sua construção, ao lado de outras entidades que congregam pesquisadores e professores de educação e ciências sociais, em particular a ANPED e seu Grupo de Trabalho sobre Estado e Políticas Educacionais. (SANDER, 2007, n/p).

Sobre a criação da Associação Nacional de Pós-Graduação e Pesquisa em Educação (ANPEd), em 1976, e do Grupo de Trabalho (GT) sobre Estado e Políticas Educacionais, criado em 1986, durante a $9^{a}$ Reunião Anual da ANPEd, Stremel (2016) discorre como sendo um acontecimento significativo do campo acadêmico da política educacional, assim como a criação e configuração de outras entidades no período de 1979, a exemplo do Centro de Estudos Educacionais e Sociedades (CEDES) e da Associação Nacional de Educação (ANDE). Nesse trilhar, vemos aflorar, na década subsequente, anos de 1980, o engajamento coletivo de entidades em prol da luta pela redemocratização do país, pautando, dentre outras questões, um amplo debate sobre as questões educacionais, adubando terreno para a realização da I Conferência Brasileira de Educação (CBE), realizada na cidade de São Paulo.

Como bem discorre Stremel (2016),

[...] essas associações científicas tiveram uma contribuição importante na medida em que participaram dos movimentos do campo educacional para a reorganização da educação brasileira e promoveram eventos que agregaram diversos pesquisadores e educadores para debater amplamente temas da política educacional brasileira (STREMEL, 2016, p. 122).

Assim, concordamos com Stremel (2016) quanto à assertiva de haver uma dupla dimensão na caracterização construtiva do campo da política educacional no Brasil, isto é, um campo de investigação acadêmica, em vinculação a um campo da ação e articulação política, consolidando, assim, uma dupla agenda de atuação no seu processo constitutivo.

Imbuídos dessas preleções sobre a constituição do campo de pesquisa em Políticas Públicas Educacionais no Brasil, avancemos para apreender os procedimentos metodológicos utilizados no levantamento dos dados sobre 
os Grupos de Pesquisas das universidades públicas da região Norte e alguns de seus achados.

\section{PROCEDIMENTOS METODOLÓGICOS DA BUSCA NO DGP}

Conforme explica o Manual do Usuário do Diretório dos Grupos de Pesquisa (DGP) ${ }^{8}$, o sistema foi desenvolvido com o intuito de compor informações dos grupos de pesquisa existentes nas instituições de ensino e de pesquisa brasileiras, onde as coletas das informações são efetivadas por meio de um formulário eletrônico, constituindo uma base sólida de dados que é disponibilizada à sociedade em geral através do website http://lattes.cnpq.br/web/dgp.

Constam na base de dados, informações como: recursos humanos constituintes dos grupos (pesquisadores, estudantes e técnicos), linhas de pesquisa em andamento, especialidades do conhecimento, setores de aplicação envolvidos, produção científica, tecnológica e artística e parcerias entre grupos e instituições. Vale lembrar que as informações sistematizadas se encontram situados no tempo e espaço, isto é, além das demarcações de temporalidade dos Grupos de Pesquisa e suas atividades, constam também a fixação por região, Unidade Federativa, instituições de ensino.

Nesses termos, são "Essas informações constituem a chamada Base corrente do DGP, atualizada continuamente pelos participantes. De dois em dois anos, o CNPq tira uma "fotografia" dessa base para a realização de censos" (CNPq/DGP, 20--, P. 03). Feitas essas breves considerações sobre o DGP, sigamos para compreender os procedimentos adotados com vistas ao estabelecimento de parâmetros de busca na base de dados.

A consulta parametrizada na Base Corrente do DGP9 fora orientada por algumas diretrizes. Optamos por utilizar como descritor, no item Termo de

\footnotetext{
8 Disponível em http://lattes.cnpq.br/web/dgp/manual-do-usuario Acesso em 23 de outubro de 2021.

9 Disponível em http://dgp.cnpq.br/dgp/faces/consulta/consulta_parametrizada.jsf Acesso em 23 de outubro de 2021.
} 
Busca, as palavras "Política Pública"10, dado o interesse em traçar a Consulta por Grupos de Pesquisa que se vinculam à área. Em seguida, aplicamos a busca aos campos Nome de grupo; Nome da linha de pesquisa; e Palavrachave da linha de pesquisa, tendo em vista o entendimento de que, se um Grupo se identifica com a temática, concomitantemente, ele o associará em uma das opções aplicadas.

As opções concernentes à Situação dos grupos, "Certificado" e "Nãoatualizado", foram conjuntamente marcadas. Vale explicar que, por grupo "Certificado", compreendemos aquele Grupo de Pesquisa enviado ao diretório pelo líder do grupo ${ }^{11}$, analisado e aprovado pelo Conselho Nacional de Desenvolvimento Científico e Tecnológico (CNPq), por meio do Dirigente de pesquisa12 da instituição que o abriga. Por sua vez, grupo "Nãoatualizado" refere- se ao grupo certificado que permaneceu sem alterações no período superior a 12 (doze) meses.

Quanto ao item Filtro para localização e tempo de existência do grupo, marcamos a Região "Norte", considerando "Todas" as Unidades Federativas (Acre, Amapá, Amazonas, Pará, Rondônia, Roraima e Tocantins) disponíveis no banco de dados e "Todas" as instituições de pesquisa sem estabelecer "Data da criação do grupo". Como Filtro para área do conhecimento e Setor de aplicação, optamos por estabelecer como item Predominante do grupo a Grande área "Ciências Humanas" na Área de "educação", e o Setor de Aplicação na Seção e Divisão marcada com a opção "educação".

Desse modo, levamos em consideração objetivamente: a área do conhecimento e a área de pesquisa, a certificação, a região geográfica e as instituições às quais os Grupos de Pesquisa pertencem. A partir de tais parâmetros, obtivemos como resultado um montante de 95 (novamente e

\footnotetext{
10 Optamos por não utilizar a palavra "Educação", dado que o filtro da Área foi marcado.

11 Líder cadastrado no DGP pelo Dirigente ou Assessor da sua instituição, responsável pelo preenchimento, atualização e envio dos dados do(s) seu(s) grupo(s) (CNPq/DGP, 20--, p. 05). 12 Representantes cadastrados no Diretório de Instituições - DI do CNPq, gestores do DGP em sua instituição, e que possuem as tarefas de cadastrar líderes e certificar grupos, entre outras (CNPq/DGP, 20--, p. 04).
} 
cinco) Grupos de Pesquisa registrados sob a guarida de "Política Pública", na região Norte, os quais foram agrupados em categorias para fins de análise.

\section{APRESENTAÇÃO E ANÁLISE DOS DADOS}

Em um primeiro momento, pautamos a identificação do quantitativo dos Grupos de Pesquisa da área de educação da região Norte, para posteriormente filtrar a quantidade específica de Grupos que versam sobre a temática "Política Pública", considerando a declarada área. Nessa direção, constatamos o registro total de 462 (quatrocentos e sessenta e dois) Grupos na Base corrente do DGP, no contexto de 16 de setembro de 2021; e, desse montante, 95 (novamente e cinco) declaravam atuar diretamente com a temática "Política Pública".

A título de melhor compreensão dessa composição, a Figura 1 ilustra a distribuição percentual dos Grupos de Pesquisa em Política Pública Educacional por estados da região Norte, estando assim arranjados: Acre (04); Amazonas (13); Amapá (03); Pará (47); Rondônia (14); Roraima (02); e Tocantins (12).

FIGURA 1 - Distribuição dos grupos de pesquisa em política pública educacional em percentuais por Unidades Federadas da Região Norte

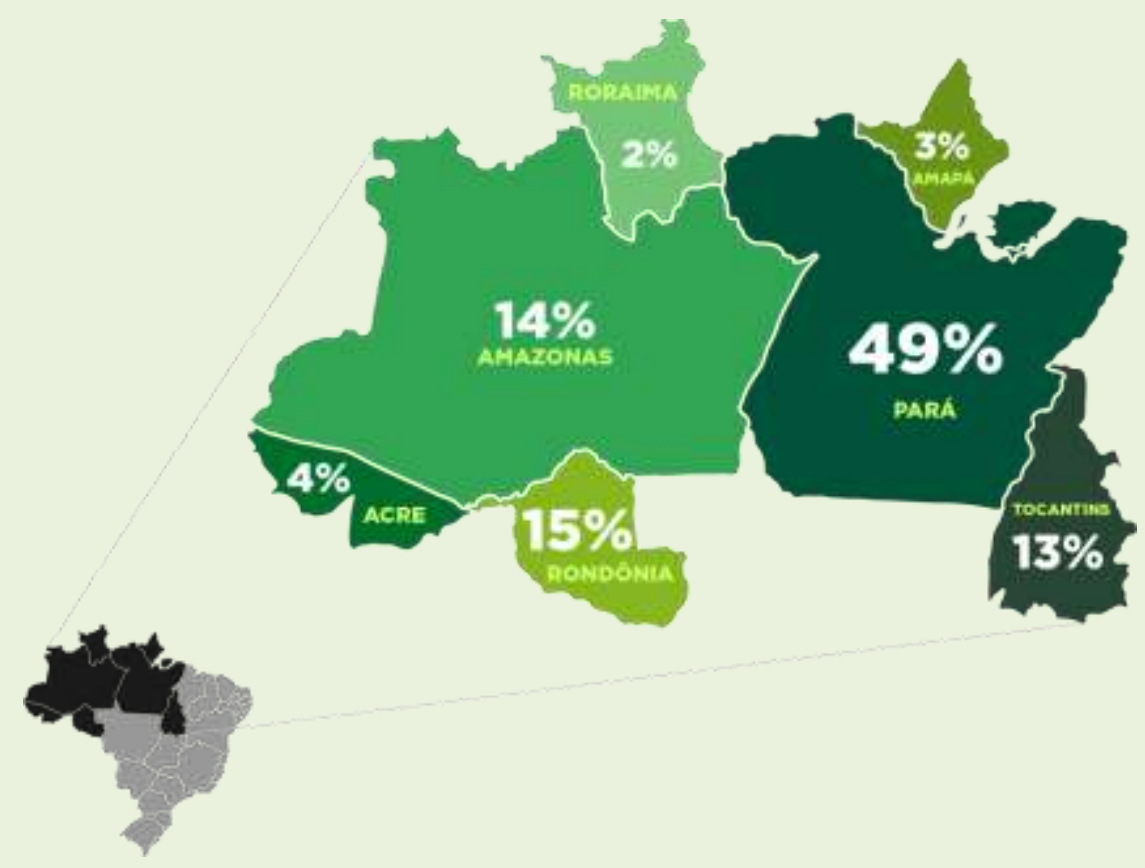

Fonte: CNPq (2021). Elaborado pelos autores e autora. 
Em vista dos dados levantados, é evidente que o estado do Pará (47) é o estado da região Norte com maior concentração de Grupos de Pesquisa em Política Pública Educacional, seguido por Rondônia (14) e Amazonas (13). Dentre algumas variáveis que contribuem para essa composição, em relação ao estado do Pará, temos que o arranjo total do estado é bem distinto das demais unidades federadas da região, a considerar que dispõe de diversas Instituições de Ensino Superior (IES), sendo quatro dessas universidades federais, uma universidade estadual e mais um instituto federal, cuja distribuição dos Grupos assim se apresenta: UFPA (29), Ufopa (06), Unifesspa (05), UEPA (05), IFPA (02).

Além disso, a UFPA, como a instituição que mantém a maior quantidade de Grupos de Pesquisa, dispõe, também, do maior quadro de docentes das universidades públicas federais da região Norte: são 2.498 (dois mil quatrocentos e novamente e oito) docentes, sendo que $79,7 \%$ desses profissionais possui título de Doutor(a)/Pós-Doutor(a). Uma outra variável é a do seu orçamento executado no ano de 2020, uma cifra de $R \$$ 1.591.408.485,05 (um bilhão e quinhentos e noventa e um milhões e quatrocentos e oito mil e quatrocentos e oitenta e cinco reais e cinco centavos) ${ }^{13}$, prefigurando o maior orçamento executado dentre as IES da região Norte.

Em uma análise inversa, ou seja, em relação ao menor quantitativo dos grupos de pesquisa, temos os estados de Roraima (02), Amapá (03) e Acre (04). Nesse particular, é importante destacar que, independentemente dos valores quantitativos dos Grupos de Pesquisa, não podemos negar o quão importante e relevante são as suas atuações sociais, especialmente frente às pesquisas, publicações e ações formativas, que tanto contribuem para 0 desenvolvimento do cenário educacional e político regional onde encontram-se estabelecidos os referidos grupos e instituições.

Vale mencionar, a título de exemplo, a atuação colaborativa do Núcleo de Pesquisas em Política Educacional, Gestão e Financiamento da

13 Conforme UFPA em Números 2021, ano base 2020. Disponível em http://www.ufpanumeros.ufpa.br/ acesso em 16 de setembro de 2021.

Revista Exitus, Santarém/PA, Vol. 12, p. 01 - 22, e022015, 2022. 
Educação (Nupgefe) da Universidade Federal do Acre, junto ao Centro Colaborador de Apoio ao Monitoramento e à Gestão de Programas Educacionais, o Cecampe Região Norte, que atua na perspectiva do ensino, pesquisa e extensão, desenvolvendo diversas ações voltadas para a qualificação da execução do Programa Dinheiro Direto na Escola (PDDE) e suas ações agregadas, além da política de Transporte Escolar (PNATE e Caminho da Escola).

Na sequência, O Figura 2, detalha a composição quantitativa dos Grupos de Pesquisa a partir das universidades federais públicas da região Norte.

FIGURA 2 - Distribuição dos grupos de pesquisa em política pública educacional da região norte por IES da Região Norte

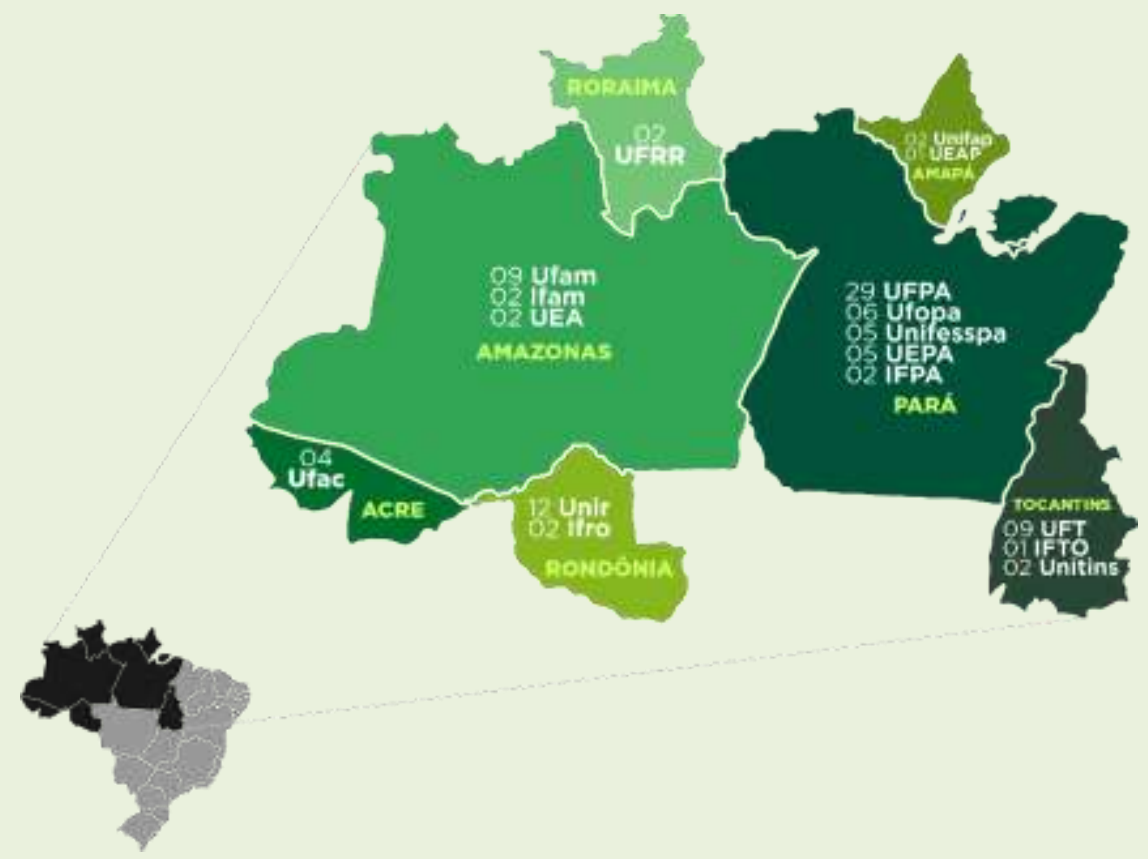

Fonte: CNPq (2021). Elaborado pelos autores e autora.

Observamos, nos dados levantados, que, no total das 11 (onze) universidades federais da região Norte, não constam representadas somente a Universidade Federal Rural da Amazônia (UFRA), e a Universidade Federal do Norte do Tocantins (UFNT). Em relação à UFRA, pode-se inferir que, possivelmente, o resultado estaria relacionado a uma maior propensão pela 
oferta de cursos bacharelados em detrimento das licenciaturas, além da inexistência de uma pós-graduação stricto sensu em educação.

Relativamente à UFNT, há de se considerar sua recente constituição institucional resultante do desmembramento de Campus da Fundação Universidade Federal do Tocantins pela Lei no 13.856, de 8 de julho de 2019. Embora sancionada nesse período, é importante destacar que as discussões que ensejavam a instituição de um campus específico para $\bigcirc$ Norte do Tocantins, resulta do Projeto de Lei (PL) n 5.274/2016 de preposição do poder executivo, e remonta a gestão da Presidenta Dilma Rousseff.

Como mencionando anteriormente, a UFPA (29) figura como sendo a IES pública da região Norte que mais comporta Grupos de Pesquisa em Política Pública Educacional, seguida por: Unir (12); UFT (09); Ufam (09); Ufopa (06); Unifesspa (05); Ufac (04); Unifap (02); e UFRR (02).

Em relação às universidades estaduais, a Uepa (05) comporta a maior quantidade de Grupos, seguida por: Unitins (02); UEA (02); UEAP (01). Dentre as cincos IES estaduais da região Norte, somente a Universidade Estadual de Roraima (UERR) não constou registrada na base de dados, os demais estados não citados não possuem uma IES estatual.

Os Institutos Federais de Educação, Ciência e Tecnologia também compõem o tecido de instituições que abrigam os Grupos de Pesquisa em Política Pública Educacional, apresentando-se assim distribuídos: IFPA (02); Ufam (02); Ifro (02); e IFTO (01). Não compuseram essa formação o Instituto Federal de Educação, Ciência e Tecnologia do Acre (lfac); o Instituto Federal de Educação, Ciência e Tecnologia do Amapá (Ifap); e Instituto Federal de Educação, Ciência e Tecnologia de Roraima (IFRR).

Como observamos, a maior representativa dos Grupos de Pesquisa em Política Educacional da Região Norte encontra-se nas universidades federais. Nesse sentido, por entendermos que esses são dados mais representativos e abrangentes dos estados da região, optamos, aqui, por traçar os perfis dos Grupos de Pesquisa, de seus respectivos líderes e linhas de pesquisa somente nas universidades federais. Ao considerarmos essa opção, a amostra da análise passou a ser de 78 (setenta e oito) Grupos de Pesquisa. 
Assim, buscamos, a partir dos dados sistematizados, identificar informações que permitissem, minimamente, traçar os perfis dos Grupos de Pesquisa, identificando a partir dos seguintes descritores: instituição de vínculo; situação; ano de formação; nome; líder(es) e linhas de pesquisa dos Grupos.

No que se refere ao item "Situação do grupo", constatamos as seguintes variáveis: Certificado (50); Certificado - Não-atualizado (16); Excluído (07); e Em preenchimento ${ }^{14}$ (05).

FIGURA 3 - Situação dos grupos de pesquisa em política pública educacional nas universidades federais da Região Norte

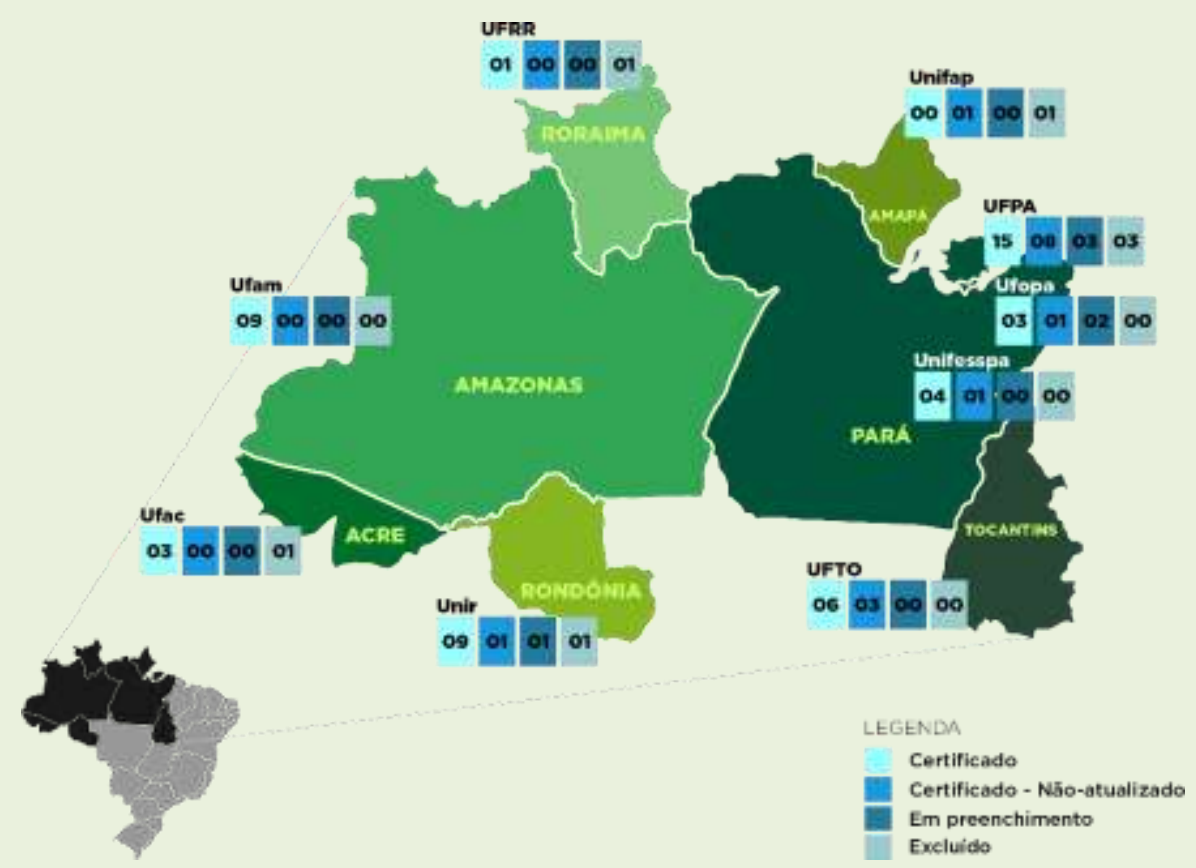

Fonte: CNPq (2021). Elaborado pelos autores e autora.

Por esse ângulo de análise e de forma mais detalhada, constatamos que com exceção da Unifap, todas as demais universidades federais da Região Norte dispõem com uma maior configuração de grupos "Certificado", em relação aos demais "Situação do grupo", isto é, grupos de pesquisa cadastrados e enviados pelos líderes de suas respectivas instituições e que foram analisados, aprovados e certificados pelo Conselho Nacional de

14 Um grupo novo ou um grupo em qualquer situação que esteja sendo alterado pelo líder, ainda não enviado ao CNPq, fica na situação "Em preenchimento" (CNPq/DGP, 20--, p. 36). 
Desenvolvimento Científico e Tecnológico, a partir do envio feito pela instância acadêmica que coordenada a pesquisa na instituição proponente. Nesse particular merece destaque a Ufam com todos seus grupos cadastrados e "Certificados", seguida da Ufac e da UFRR.

Outro cenário é aquele referente aos grupos que constam como "Certificado - Não - atualizado", identificando-se na UFPA a maior quantidade deles.

Referente os grupos com status situacional de "Excluído" importa destacar que das 09 (nove) universidades federais, constatamos que 05 (cinco) IFES apresentam esse status, a saber: Ufac (01); UFRR (01); Unir (01); Unifap (01) e UFOPA (03). "Um grupo que foi "Excluído" pelo líder (ou pelo CNPq, de acordo com as regras de validade de grupos, explicitadas no FAQ do Portal do DGP) não tem como ter a situação alterada ou revertida". (CNPq/DGP, 20--, p. 37). Se o(a) líder excluir o grupo acidentalmente, terá que cadastrar o novo grupo novamente. Vale sinalizar, que a base de dados não informa o motivo da exclusão.

Por sua vez, os grupos em situação de "Em preenchimento", que tratam de um "grupo novo ou um grupo em qualquer situação que esteja sendo alterado pelo líder, ainda não enviado ao CNPq" (CNPq/DGP, 20--, p. 36), notamos que, dentro dos quatro status analisados verificados, prefiguram-se quantitativamente em menor escala nas seguintes IFES: Unir (01); UFPA (02) e Ufopa (02).

No que se refere ao ano de formação dos Grupos, o registro mais longevo é datado do ano de 1982, trata-se do Grupo de Pesquisa Interdisciplinar em Educação Ambiental no contexto amazônico, vinculado à Universidade Federal de Rondônia (Unir), criado pelo líder Prof. Dr. Clarides Henrich de Barba. Ainda nessa década, identificamos, também, o Núcleo de Estudos, Experiências e Pesquisas Educacionais, instituído no ano de 1989 pelas líderes Profa. Dra. Ronney da Silva Feitoza e Profa. Dra. Antonia Silva de Lima, vinculado à Universidade Federal do Amazonas (Ufam). Destacamos que ambos os grupos mais longevos se encontram "Certificados". 
O Gráfico 1 objetiva apresentar mais detalhadamente a composição em relação ao ano de formação dos Grupos. Vale lembrar que o resultado dessa composição constitui a somatória de todos os Grupos das universidades federais da Região Norte, inclusive aqueles que foram "Excluídos". Com observamos, em um período relativamente recente, no ano de 2018, temos a maior taxa (08) de criação de Grupos de Pesquisa, seguido do ano de 2020 e 2013, com uma composição de 07 (sete) e 06 (seis) Grupos.

Coincidência ou não, chama atenção que, em ambos os períodos em que se registraram as maiores taxa de criação de Grupos de Pesquisa, tínhamos, no cenário sociopolítico brasileiro, intensas disputas hegemônicas de poder, cujo eventos simbólicos foram as Jornadas de junho de 201315, as Eleições presidenciais 2018 e, em 2020, a intensificação de ataques a educação pública e gratuita, por parte da gestão do atual governo federal. Em perspectiva análoga, vale lembrar que a criação das principais associações de pesquisas do campo educacional, como verificado em Stremel (2016), também se deu em um cenário sociopolítico de intensas disputas.

GRÁFICO 1 - Distribuição dos grupos de pesquisa em política pública educacional nas universidades federais da Região Norte por ano de formação

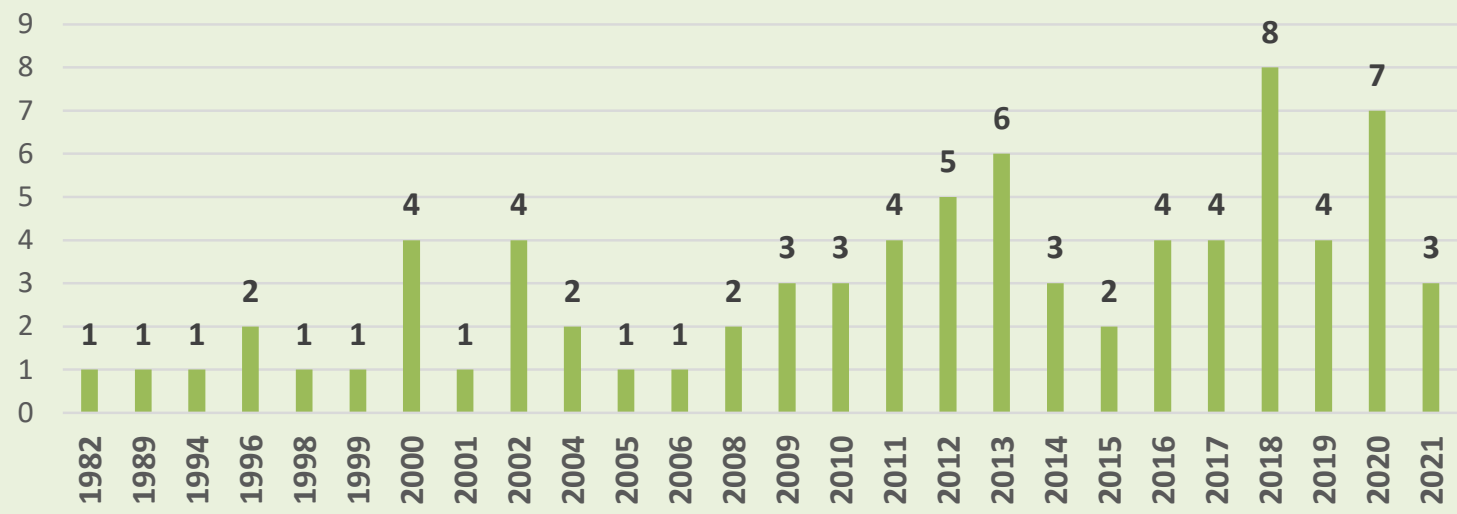

Fonte: CNPq (2021). Elaborado pelos autores e autora.

15 Para se ter uma vista mais ampla, ver https://blogdaboitempo.com.br/jornadas-de-junho/ Acesso em 23 de outubro de 2020.

Revista Exitus, Santarém/PA, Vol. 12, p. 01 - 22, e022015, 2022. 
Pela amostra dos nomes dos(as) líderes dos Grupos Certificado; Certificado - Não- atualizado; e Em preenchimento; extraímos duas variáveis, o sexo e a titulação dos(as) pesquisadores(as), cujos resultados foram: 22 (vinte e dois) do sexo masculino e 49 (quarenta e nove) do sexo feminino. Referente à titulação, constatamos a existência de 06 mestres(as), 37 doutores(as) e 28 professores(as) pesquisadores que já realizaram estágio pós-doutoral. Sobre esse quesito, temos a seguinte forma de distribuição, de acordo com os percentuais:

FIGURA 4 - Sexo dos(as) líderes dos grupos de pesquisa em política pública educacional das universidades federais da Região Norte

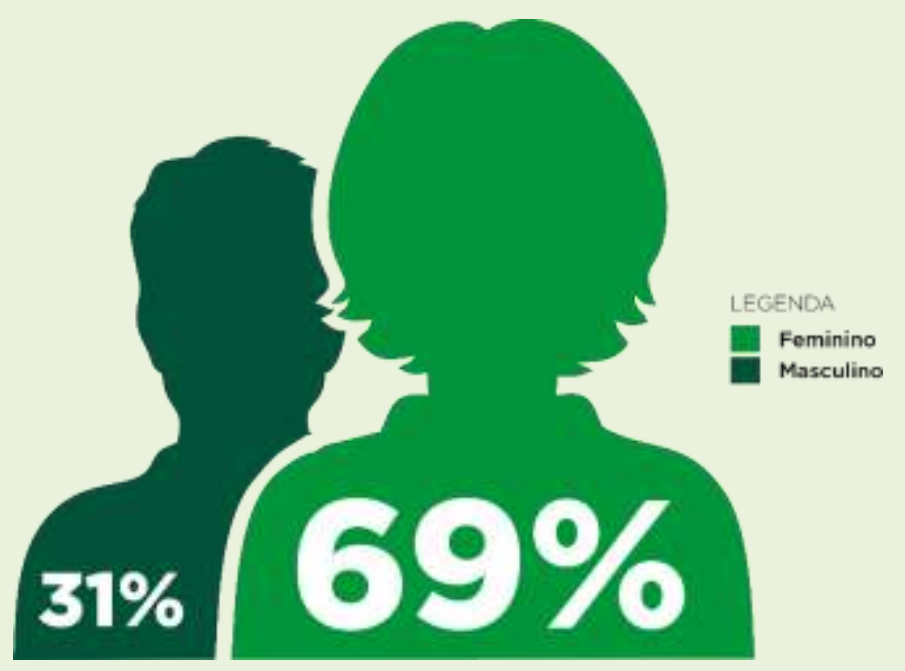

FIGURA 5 - Titulação dos(as) líderes dos grupos de pesquisa em política pública educacional das universidades federais da Região Norte

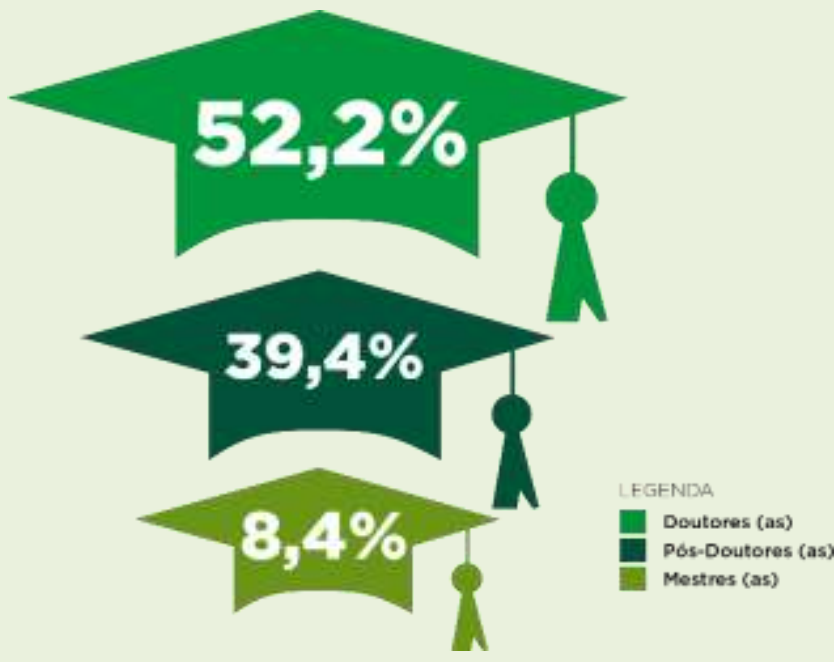

Fonte: CNPq (2021). Elaborado pelos autores e autora 
Por um lado, o conjunto total dos docentes do sexo masculino das universidades federais da região Norte apresenta uma maior quantidade, em torno de 7.788 (sete mil e setecentos e oitenta e oito) em relação às 6.985 (seis mil e novecentos e oitenta e cinco) docentes do sexo feminino, conforme os dados do Censo da Educação Superior 2019, Inep (2020); por outro, no tocante à composição da variável sexo dos(as) líderes dos Grupos de Pesquisa em Políticas Públicas Educacionais, essa condição é totalmente inversa, conforme pode ser visto na Figura 4.

Em relação às titulações dos(as) líderes dos Grupos, observamos que são, em sua maioria, doutores(as), em uma distribuição percentual de 53\% titulados(as), sendo que $39,4 \%$ destes(as) possuem pós-doutorado. Essa constatação leva a inferir que o campo de pesquisa em Políticas Educacionais na região Norte é um campo altamente experiente, qualificado e com forte inserção na pesquisa e na pós-graduação.

Quanto às Linhas de Pesquisa dos Grupos, sinalizamos que preferimos não categorizar os Grupos de Pesquisa, por considerarmos que a melhor vista para fins de categorização seria por meio da análise mais detalhada - o que demandaria mais tempo - como, por exemplo, por meio das suas publicações (artigos, livros, dissertações, teses e outras).

Ademais, alguns Grupos de Pesquisa apresentam, no indicativo de linha de pesquisa, somente o termo "Políticas Públicas Educacionais", o que pode dar margem para uma gama de interpretações acerca de suas ênfases e atuações. Assim, optamos por apontar os 22 principais segmentos recorrentes nas descrições das linhas de pesquisa dos Grupos, conforme explicita a tabela a seguir:

QUADRO 1 - Indexadores recorrentes nas descrições das linhas de pesquisa

\begin{tabular}{|l|c|}
\hline \multicolumn{1}{|c|}{ Segmentos recorrentes } & $\begin{array}{c}\text { Quantidade de } \\
\text { ocorrências }\end{array}$ \\
\hline Política & 82 \\
\hline Pública & 53 \\
\hline Educação & 43 \\
\hline Educacional & 28 \\
\hline Gestão & 15 \\
\hline
\end{tabular}




\begin{tabular}{|l|c|}
\hline Básica & 12 \\
\hline Estado & 11 \\
\hline Formação & 08 \\
\hline Escolar; Professor & 06 \\
\hline Prático & 05 \\
\hline Avalição; Currículo; Financiamento; Social & 04 \\
\hline Amazônia; Cultura; Direito; Educativo; Infância; Sociedade; Superior & 03 \\
\hline
\end{tabular}

Fonte: Elaborado pelos autores e autora com auxílio do software IRaMuteQ.

Nesse movimento, apontamos subcampos de atuação dos Grupos de Pesquisa, e a sistematização dos principais segmentos recorrentes nas descrições das linhas pesquisa. Por essa razão, foi possível observar a manifestação de diversos subcampos de atuação, considerando o campo maior, as Políticas Públicas Educacionais, como ilustra a Figura 6.

FIGURA 6 - Nuvem de palavras dos indexadores recorrentes nas descrições das linhas de pesquisa

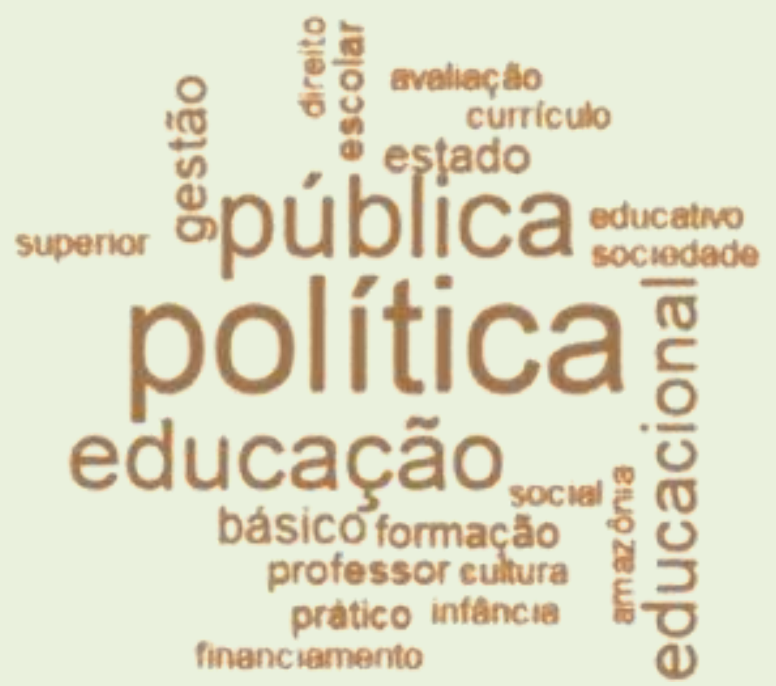

Fonte: Elaborado pelos autores e autora com auxílio do software IRaMuteQ

Destacamos, ainda, que as linhas de pesquisas dos Grupos perpassam por todos os níveis, etapas e modalidades da educação. Alguns grupos não apresentam linhas específicas com designação do segmento "política". Entretanto, esboçam sua atuação na área por meio do campo das Repercussões dos trabalhos do grupo. A exemplo do Grupo de Estudos e Pesquisas em Criança, Infância e Educação Infantil - IPÊ, vinculado à Universidade Federal do Pará (UFPA), que descreve que "Seus integrantes 
têm participado ativamente de processos de discussões e elaborações de políticas nacionais de Educação Infantil".

\section{CONSIDERAÇÕES FINAIS}

Neste artigo, buscamos mapear os Grupos de Pesquisa em Política Pública Educacional da região Norte, a partir dos dados disponibilizados no Diretório dos Grupos de Pesquisa (DGP) do Conselho Nacional de Desenvolvimento Científico e Tecnológico (CNPq). Tal processo viabilizou uma breve compressão da dimensão destes, como instrumentos propulsores no âmbito da pesquisa, ao passo que foi possível observar como estão organizados e direcionados rumo à produção do conhecimento de caráter científico, em um ambiente amplamente qualificado e motivador, que tem possibilitado e possibilita aos(às) professores(as)/pesquisadores(as), em diferentes subáreas, um diálogo sobre uma mesma temática, a Política Pública Educacional no contexto da região Norte.

Inegavelmente, essa organização, nomeada Grupo de Pesquisa, em razão da formação diversificada de membros, possibilita um ambiente de trabalho com uma visão mais ampla do objeto estudado, e totalmente respaldado por uma vasta experiência, cumprindo, assim, uma importante função no campo da formação, da pesquisa, seja na dimensão acadêmica ou no âmbito político os Grupos de Pesquisa. Constituem-se em uma ponte para a composição intelectual e coletiva científica nas Instituições de Ensino Superior (IES) públicas.

Nessa direção, esperamos que os resultados aqui reportados subsidiem a comunicabilidade entre os(as) pesquisadores(as), estudantes, professores(as), e interessados pela temática, em especial da região Norte, de modo que contribua no trato do planejamento de ações colaborativas, seja na dimensão das pesquisas ou na atuação política direta, visando intervenções qualificadas e pontuais no campo educacional na/da Amazônia brasileira. 


\section{REFERÊNCIAS}

FREIRE, P. Política e Educação. São Paulo: Cortez Editora, 1993.

INSTITUTO NACIONAL DE ESTUDOS E PESQUISAS EDUCACIONAIS ANÍSIO TEIXEIRA. Sinopse Estatística da Educação Superior 2019. Brasília: Inep, 2020. Disponívelem: http://portal.inep.gov.br/basica-censo-escolar-sinopsesinopse. Acesso em: 20 de dezembro de 2020.

STREMEL, S. A constituição do campo acadêmico da política educacional no Brasil. 2016. 315 f. Tese (Doutorado em Educação) - Universidade Estadual de Ponta Grossa, Ponta Grossa, 2016.

SANDER, B. Introdução à história da ANPAE como sociedade civil no campo da educação. Versão revisada e atualizada do ensaio intitulado A genealogia do conhecimento da administração da educação do Brasil e o papel da Anpae como entidade da sociedade civil. In: XXII SIMPÓsIO

Brasileiro de Política e Administração da Educação (2007: Porto Alegre). Por uma escola de qualidade para todos: programação e trabalhos completos. Organizador Benno Sander. Niterói, RJ: ANPAE; Porto Alegre, RS:

UFRGS/FACED/PPGEDU, Série Cadernos ANPAE, n. 4, 2007.

CNPq, Conselho Nacional de Desenvolvimento Científico e Tecnológico.

Diretório dos Grupos de Pesquisa no Brasil. Disponível em: http://dgp.cnpq.br . Acesso em 21 de dezembro de 2020.

CNPq, Conselho Nacional de Desenvolvimento Científico e Tecnológico. Manual do usuário - do Diretório dos Grupos de Pesquisa no Brasil. Disponível em: http://lattes.cnpq.br/web/dgp/manual-do-usuario. Acesso em 23 de outubro de 2021.

Recebido em: 12 de outubro de 2021. Aprovado em: 30 de dezembro de 2021.

Publicado em: 21 de janeiro de 2022.

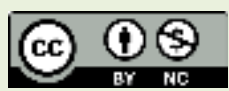

